\title{
The Effect of Synthetic C-Reactive Protein on the In Vitro Immune Response of Human PBMCs Stimulated with Bacterial Reagents
}

\author{
Atsushi Sato, ${ }^{1}$ Hiroyuki Nakashima, ${ }^{1}$ Manabu Kinoshita, ${ }^{1}$ Masahiro Nakashima, ${ }^{1}$ \\ Yoshiko Ogawa, ${ }^{1}$ Satoshi Shono, ${ }^{1}$ Masami Ikarashi, ${ }^{1}$ and Shuhji Seki ${ }^{1,2}$
}

\begin{abstract}
Synthetic C-reactive protein (CRP) rescues mice from lethal endotoxin shock or bacterial infection by suppressing tumor necrosis factor (TNF- $\alpha$ ), but in turn, enhances Kupffer cell phagocytic activity. We herein assessed the influence of CRP in human peripheral blood mononuclear cells (PBMCs). When human PBMCs were stimulated in vitro with penicillin-treated Streptococcus pyogenes, bacterial DNA motifs and lipopolysaccharide with or without synthetic CRP, CRP suppressed the production of TNF- $\alpha$ and IL-12, but not that of IFN- $\gamma$. This was also the case for the in vitro Shwartzman reaction induced in PBMCs. CRP also decreased high-mobility group box 1 production from macrophages, which is crucial in the later phase of endotoxin/septic shock. However, CRP upregulated the perforin expression by $\mathrm{CD} 56^{+} \mathrm{NK}$ cells and increased their antitumor cytotoxicity. CRP may thus be a potent immunomodulatory factor in the human immune system, suggesting its therapeutic potential for use against human septic shock.
\end{abstract}

KEY WORDS: inflammation; C-reactive protein; tumor necrosis factor- $\alpha$; high-mobility group box 1 ; human PBMCs.

\section{INTRODUCTION}

C-reactive protein (CRP), named for its capacity to precipitate the somatic C-polysaccharide of Streptococcus pneumoniae, is an acute-phase protein produced by hepatocytes in response to infections and tissue damage $[1,2]$. Several reports suggested that CRP as well as functional CRP peptides have positive and regulatory effect on the innate immunity against infections and tumors $[3,4]$, however, the role of CRP on innate immunity has

\footnotetext{
${ }^{1}$ Department of Immunology and microbiology, National Defense Medical College, Namiki 3-2, Tokorozawa, Saitama 359-8513, Japan

${ }^{2}$ To whom correspondence should be addressed at Department of Immunology and microbiology, National Defense Medical College, Namiki 3-2, Tokorozawa, Saitama 359-8513, Japan. E-mail: btraums@ndmc.ac.jp
}

Abbreviations: CRP, C-reactive protein; PBMCs, Peripheral blood mononuclear cells; HMGB1, High-mobility group box 1; LPS, Lipopolysaccharide; E. coli, Escherichia coli; PBS, Phosphate-buffered saline; RPMI, Roswell Park Memorial Institute; FBS, Fetal bovine serum; ELISA, Enzyme-linked immunosorbent assay; TNF, Tumor necrosis factor-alpha; IFN- $\gamma$, Interferon gamma not been fully elucidated. We have recently reported that pretreatment with synthetic CRP prevents mice from developing either lethal endotoxemia or $E$. coli infection by suppressing TNF production, while it simultaneously enhances the phagocytic activity of Kupffer cells. Even if it is used after the onset of $E$. coli infection, synthetic CRP decreases the mouse mortality [5]. It also prevents mice from developing either generalized Shwartzman reaction or multi-organ failure induced by consecutive injection of IL-12 and LPS into mice by inhibiting TNF production [5]. Shwartzman reaction-like response was also reproduced by human PBMCs in vitro [6].

Innate immune cells, macrophages, produce proinflammatory cytokines, such as TNF and IL-12, after activation with LPS via toll-like receptor (TLR)-4 or hypomethylated common bacterial DNA motifs (CpGODN) via toll-like receptor-9 [7]. IL-12 produced by macrophages/Kupffer cells stimulates natural killer (NK) cells and NKT cells to produce another proinflammatory cytokine, IFN- $\gamma$, which in turn activates macrophages/ Kupffer cells to increase their phagocytosis and cytokine production in a positive feedback loop [7]. These 
reactions are indispensable for effective suppression of the growth and dissemination of invading bacteria. Bacterial activation may also increase the function of innate immune cells to survey and suppress tumor growth. Human TCR $(-)$ mononuclear cells with NK cell markers CD56 or CD57 are known to correspond to mouse NK cells having the antitumor cytotoxicity $[8,9]$. Human NK cells express either CD56 or CD57 and CD56 ${ }^{+} \mathrm{NK}$ cells usually show more potent antitumor cytotoxicity than $\mathrm{CD} 57^{+} \mathrm{NK}$ cells [10]. These CD56 ${ }^{+} \mathrm{NK}$ cells and $\mathrm{CD} 56^{+} \mathrm{T}$ (human NKT) cells play a primary role in the elimination of tumor cells when activated with cytokines, IL-2 and IL-12 or bacterial stimulation $[8,11,12,9]$. On the other hand, uncontrolled activation of macrophages/Kupffer cells, NK cells and NKT cells in mice causes vascular endothelial cell damage and exacerbates multi-organ dysfunction syndrome (MODS) induced by LPS [9, 13-15].

High mobility group box 1 (HMGB1) is usually located in the cytosol and nucleus of macrophages, but is secreted from macrophages in response to bacterial infections and acts as a proinflammatory cytokine. HMGB1 is now known to be a crucial late mediator of septic shock and MODS [16-18].

In the present study, we investigated how CRP affects the functions of macrophages and NK cells in human PBMCs after stimulation with a streptococcus reagent (OK-432), CpG-ODN, LPS or during in vitro Shwartzman-like reaction. Consistent with our recent report using a mouse model [5], we observed that CRP decreases the production of proinflammatory cytokines and HMGB1 from human PBMCs stimulated with these reagents, without decreasing the IFN- $\gamma$ production. In addition, CRP increased the antitumor activity of NK cells.

\section{MATERIALS AND METHODS}

\section{Peripheral Blood Samples}

Heparinized peripheral blood samples were obtained several times from eight healthy adult volunteers. We obtained informed consent from all volunteers and also received approval from the ethics committee of our medical school.

\section{Reagents}

Synthetic CRP peptide (174-185) was purchased from BACHEM (King of Prussia, PA, USA). Penicillintreated Streptococcus pyogenes (OK-432) was purchased from Chugai (Tokyo, Japan). Human CpG-ODN (HC4032: TCGTCGTTTTGTCGTTTTGTCGTT) was purchased from Hycult Biotechnology (Uden, Netherlands). LPS (Escherichia coli 0111:B4) was purchased from Sigma Chemical Co. (St. Louis, MO, USA). Recombinant human IL-12 (p70) was purchased from Strathmann Biotec (Hamburg, Germany).

\section{Isolation of PBMCs and Separation of Adherent Macrophages}

Blood samples were obtained and PBMCs were isolated using a lymphocyte separation medium (MP Biomedicals., LLC-Cappel Prod, Ohio, USA) and gradient centrifugation. The gravity of the lymphocyte separation medium is $1.077-1.080 \mathrm{~g} / \mathrm{ml}$ at $20{ }^{\circ} \mathrm{C}$. PBMCs were suspended at $1 \times 10^{6}$ cells $/ \mathrm{ml}$ in RPMI 1640 containing $20 \%$ human serum and were cultured on plastic plates for $1 \mathrm{~h}$ in $5 \% \mathrm{CO}_{2}$ at $37^{\circ} \mathrm{C}$ to separate the macrophages and lymphocytes. Non-adherent lymphocytes were obtained by gentle pipetting, and subsequently, and non-adherent lymphocytes $\left(1 \times 10^{6}\right.$ cells $/ \mathrm{ml}$ ) and the remaining plastic adherent cells (mainly monocytes/macrophages, up to $20 \%$ of PBMC) were separately stimulated by bacterial reagents for the indicated periods.

\section{Co-incubation of PBMCs or Adherent Macrophages with Synthetic CRP and Bacterial Reagents (Including In Vitro Shwartzman Reaction)}

Total PBMCs $\left(1 \times 10^{6}\right.$ cells $\left./ \mathrm{ml}\right)$, adherent macrophages (usually up to $20 \%$ of PBMCs) or nonadherent lymphocytes $\left(1 \times 10^{6}\right.$ cells $\left./ \mathrm{ml}\right)$ were suspended in RPMI 1640 containing $20 \%$ human serum and were then cultured on 48 -well flat-bottom plates in $5 \% \mathrm{CO}_{2}$ at $37{ }^{\circ} \mathrm{C}$ with or without $200 \mu \mathrm{g} / \mathrm{ml}$ of synthetic CRP peptide. An aliquot of $0.5 \mu \mathrm{g} / \mathrm{ml} \mathrm{OK}-432,1.5 \mathrm{mg} / \mathrm{ml}$ CpG-ODN, $10 \mathrm{ng} / \mathrm{ml}$ LPS or PBS (as control) was added to the culture medium just after CRP administration, and the cells were cultured for $48 \mathrm{~h}$. An in vitro Shwartzman reaction was also induced in the blood cells [6]. PBMCs were cultured with $2 \mathrm{ng} / \mathrm{ml}$ of IL-12 (p70) for $24 \mathrm{~h}$ with or without CRP. A sample of $10 \mathrm{ng} / \mathrm{ml}$ of LPS was added to the culture medium and the cells were cultured for an additional $24 \mathrm{~h}$. To examine the cytokine productions from macrophages, adherent macrophages were cultured with IL-12 with or without CRP for $24 \mathrm{~h}$ and the macrophages were cultured with LPS for additional $24 \mathrm{~h}$. Four to eight independent experiments were performed. 
Assays for TNF, IFN- $\gamma$, IL-6, IL-12 (p40 and p70), IL-10 and HMGB1 Levels

The TNF, IFN- $\gamma$, IL-6, IL-12 and IL-10 levels in the culture supernatants were measured using cytokinespecific ELISA kits (OptEIATM, PharMingen, San Diego, USA). The HMGB1 level in the culture supernatants was measured using a commercially available ELISA (Shino-Test Corporation; distributed by IBL Hamburg) according to the manufacturer's directions.

\section{Flow Cytometric Analysis (Including Intracellular Staining for Perforin) of PBMCs}

A three-color immunofluorescence test was performed. PBMCs were stained with fluorescein isothiocyanate (FITC)-conjugated anti-human $\alpha \beta$ TCR Ab, phycoerythrin(PE)-conjugated anti-CD57 Ab and PC5conjugated anti-CD56 Ab. A commercially available kit (BD Cytofix/Cytoperm solution, BD Pharmingen) and a FITC-conjugated anti-human perforin Ab (Ancell corporation, Bay port, $\mathrm{MN}$ ) or isotype-matched $\mathrm{Ab}$ (antimouse IgG2bk) were used for intracellular staining of perforin. The cells were stained with PE-conjugated antiCD56 Ab and PC5-conjugated anti- $\alpha \beta$ TCR Ab, followed by staining with anti-perforin $\mathrm{Ab}$ or isotype $\mathrm{Ab}$. The cells were analyzed using the EPICS XL and FC500 devices (Beckman Coulter, Miami, FL).

\section{Cytotoxicity Assays Against Tumor Cells}

The calcein-AM-based Terascan assay was performed to estimate the effect of synthetic CRP on the cytotoxicity of PBMCs stimulated by bacterial ligands. For the cytotoxicity assays against tumor cells, NK-sensitive K562 cells (a MHC class-I negative tumor cell line) and NK-resistant Raji cells (a MHC class-I negative tumor cell line) were used as target cells. The target cells were labeled with $10 \mu \mathrm{g} /$ $\mathrm{ml}$ calcein-AM (Kohjin Bio, Saitama, Japan) for each cytotoxicity assay. The stimulated PBMCs were used as effector cells. The labeled target tumor cells were co-cultured with effector cells at $37{ }^{\circ} \mathrm{C}$ in a fully humidified $5 \% \mathrm{CO}_{2}$ atmosphere in 96-well plates for $4 \mathrm{~h}$. For the calcein-AM-based Terascan assay, the plate was placed on a microscope stage of the Terascan instrument (MinervaTech, Tokyo, Japan), which serially measured the fluorescence emitted by intact target cells during co-culture of the target and effector cells.

\section{Cell Sorting and Culture of PBMCs}

PBMCs were stained with PE-conjugated anti$\mathrm{CD} 56 \mathrm{Ab}$, anti-CD57 $\mathrm{Ab}$ or PC5-conjugated anti- $\alpha \beta$ TCR Ab. The cells were then labeled with anti-PE microbeads or anti-PC5 microbeads. CD56, CD57 or $\alpha \beta$ TCR-positive cells were depleted by magnetic-activated cell sorting system (MACS; Miltenyi Biotec $\mathrm{GmbH}$, Bergisch Gladbach, Germany). The $\mathrm{CD} 56^{+}, \mathrm{CD} 57^{+}$or $\alpha \beta \mathrm{TCR}^{+}$cell-depleted PBMCs were suspended at $1 \times 10^{6}$ cells $/ \mathrm{ml}$ in RPMI 1640 containing $20 \%$ human serum and then were cultured with stimulation by OK432, CpG-ODN or LPS with or without synthetic CRP peptide on 48-well flat-bottom plates in $5 \% \mathrm{CO}_{2}$ at $37{ }^{\circ} \mathrm{C}$ for $48 \mathrm{~h}$. After the culture, they were used for cytotoxic assays.

\section{Statistical Analysis}

Statistical analyses were performed using the StatView $4.02 \mathrm{~J}$ software package (Abacus Concepts, Berkley, CA). Statistical evaluations were made using a one-way analysis of variance [17] or a two-way ANOVA, followed by the Fisher PLSD test. The data are presented as the means \pm standard error (SE). $p<0.05$ was considered to be statistically significant.

\section{RESULTS}

The Effect of CRP on the Production of Proinflammatory Cytokines from PBMCs or Adherent Macrophages Stimulated with Bacterial Reagents

PBMCs or adherent macrophages were cultured with OK-432, CpG-ODN or LPS for $48 \mathrm{~h}$ with or without CRP. The culture supernatants were collected at the indicated time points. Synthetic CRP treatment significantly suppressed the production of TNF and IL12 but not IFN- $\gamma$ from the pathogen-stimulated PBMCs (Fig. 1). CRP decreased TNF and IL-12 production from adherent macrophages stimulated with each bacterial reagent (Fig. 2). The production of IL-6 and IL-10 from either PBMCs or adherent macrophages (except IL-6 from PBMCs) stimulated with bacterial reagents was also decreased by CRP (Fig. 3). The productions of cytokines from adherent macrophages were lower than those from PBMCs, suggesting that direct contact with lymphocytes and/or their cytokines including IFN- $\gamma$ may be needed for macrophages to produce sufficient cytokines. Non-adherent lymphocytes, including NK 
cells and $\mathrm{T}$ cells, stimulated with reagents did not produce these cytokines, if any (data not shown). In addition, CRP did not affect the weak proliferative activities of PBMCs stimulated with bacterial reagents, such as CpG-ODN or LPS for $48 \mathrm{~h}$, as demonstrated by $\left[{ }^{3} \mathrm{H}\right]$ thymidine uptake experiments (up to $3,000 \mathrm{cpm}$ ). However, a side scatter analysis of the flow cytometry showed that many lymphocytes (mainly $\mathrm{CD} 6^{+}$cells) exhibited the large blastic morphology at $48 \mathrm{~h}$ after culture with bacterial reagents (data not shown), thus indicating that they were activated.

\section{Synthetic CRP Augmented the Antitumor Cytotoxicity of PBMCs Against Raji and K562 Cells After Stimulation with Bacterial Reagents}

We examined the effects of synthetic CRP on the antitumor cytotoxicity of activated PBMCs. PBMCs were cultured with OK-432, CpG-ODN or LPS, for $48 \mathrm{~h}$ with or without synthetic CRP. Thereafter, the PBMCs were collected, and their antitumor cytotoxicity against Raji and K562 tumor cells was evaluated. The stimulated PBMCs showed potent cytotoxicity against both tumor cell lines. Co-culture with synthetic CRP further

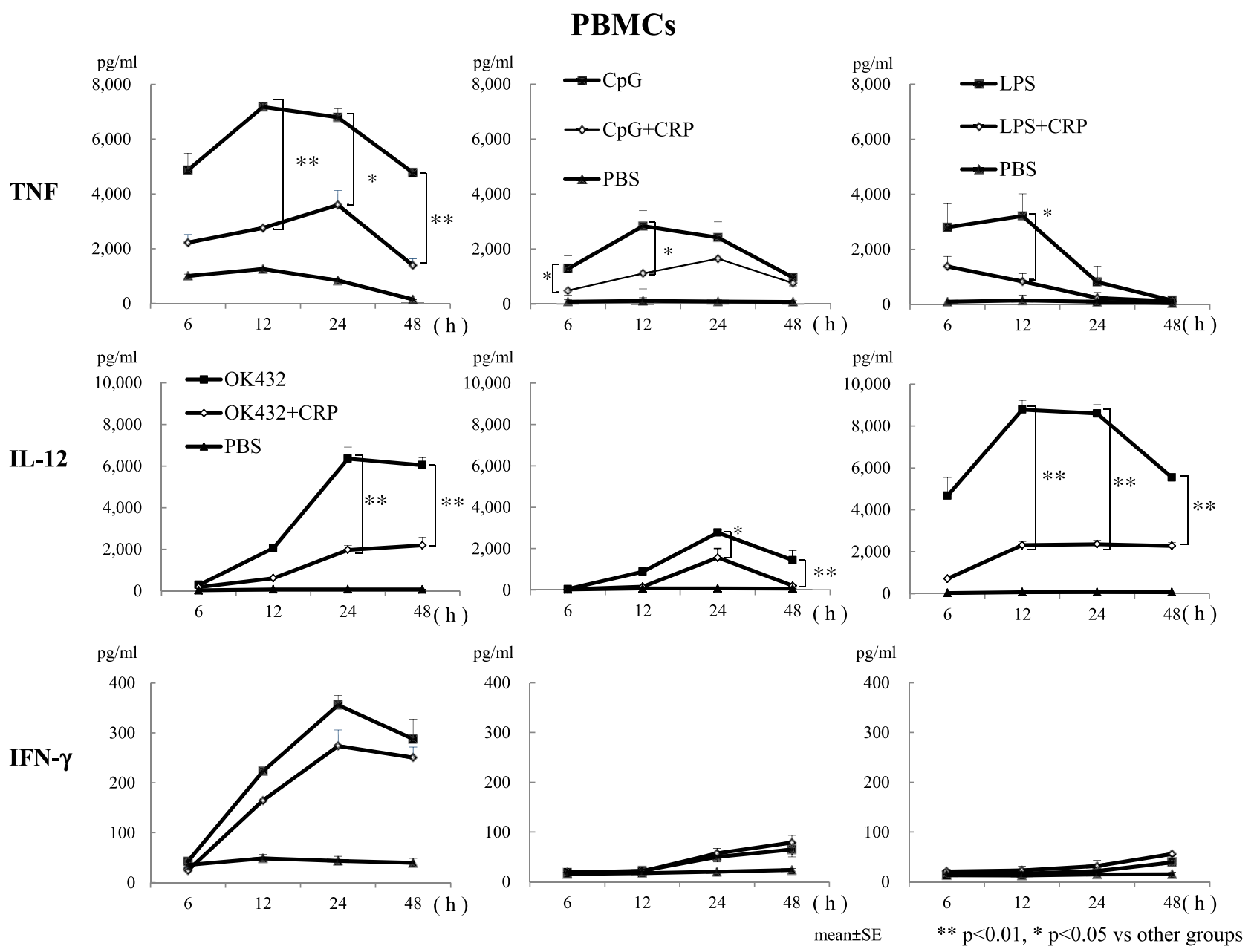

Fig. 1. Synthetic CRP modulates proinflammatory cytokine production from bacterial reagent-stimulated PBMCs. PBMCs were cultured with bacterial reagents with or without CRP for $48 \mathrm{~h}$. The culture supernatants were collected at the indicated time points and were subjected to an ELISA for TNF, IL-12 (p40\&p70) and IFN- $\gamma$. The data are presented as the means \pm SE eight independent experiments. $* * p<0.01$ vs CRP $(+)$ group by two-way ANOVA. 
augmented the antitumor cytotoxicity of these PBMCs against both K562 and Raji cells (Table 1). Depletion of $\mathrm{CD}^{2} 6^{+}$cells but not of $\mathrm{CD} 57^{+}$cells or $\alpha \beta$ T cells by magnetic beads substantially decreased the cytotoxicity of the PBMCs against both tumor cell lines (Table 2). Therefore, $\mathrm{CD}_{56}{ }^{+} \mathrm{NK}$ cells (including some $\mathrm{CD} 56^{+} \mathrm{T}$ cells) are considered to be the main antitumor effectors, although $\mathrm{T}$ cells may have some cytotoxic effects. When $\mathrm{CD}^{+} 6^{+}$cells were purified from PBMCs cultured for $48 \mathrm{~h}$ with each of the bacterial reagents and cytotoxic assays were performed, they consistently exhibited strong cytotoxicity against both K562 and Raji cells (data not shown).

\section{Synthetic CRP Increased the Intracellular Perforin in NK Cells After Bacterial Stimulation}

To examine the mechanism underlying the observed increase in the antitumor effector function of the cells, we assessed the effects of synthetic CRP on the phenotype and proportion of PBMCs stimulated with OK-432, CpG-ODN, or LPS for $48 \mathrm{~h}$. Co-culture with synthetic CRP tended to increase the proportion of
$\mathrm{CD}^{+} 6^{+} \mathrm{NK}$ cells, although the difference was not statistically significant (Fig. 4). CRP significantly increased the proportions (in percent) of perforinexpressing $\mathrm{CD}^{2} 6^{+} \mathrm{NK}$ cells and their perforin intensities in the pathogen-stimulated PBMCs (Fig. 4). In addition, synthetic CRP did not affect the weak perforin expression of $\mathrm{CD} 57^{+} \mathrm{NK}$ cells (data not shown). Therefore, the increased antitumor cytotoxicity is considered to be attributable to the functional enhancement of $\mathrm{CD} 56^{+} \mathrm{NK}$ cells.

\section{Synthetic CRP Affects the Function of PBMCs After In Vitro Shwartzman Reaction}

We previously reported that PBMCs, cultured with IL-12 (p70) for $24 \mathrm{~h}$ and with LPS for an additional $24 \mathrm{~h}$, produced a much larger amount of TNF than PBMCs without IL-12 priming (in vitro Shwartzman reaction) [6]. CRP also decreased the production of TNF and IL-12 (p40 and p70) but not IFN- $\gamma$ from PBMCs (mainly NK cells) or macrophages during in vitro Shwartzman reaction (Fig. 5).

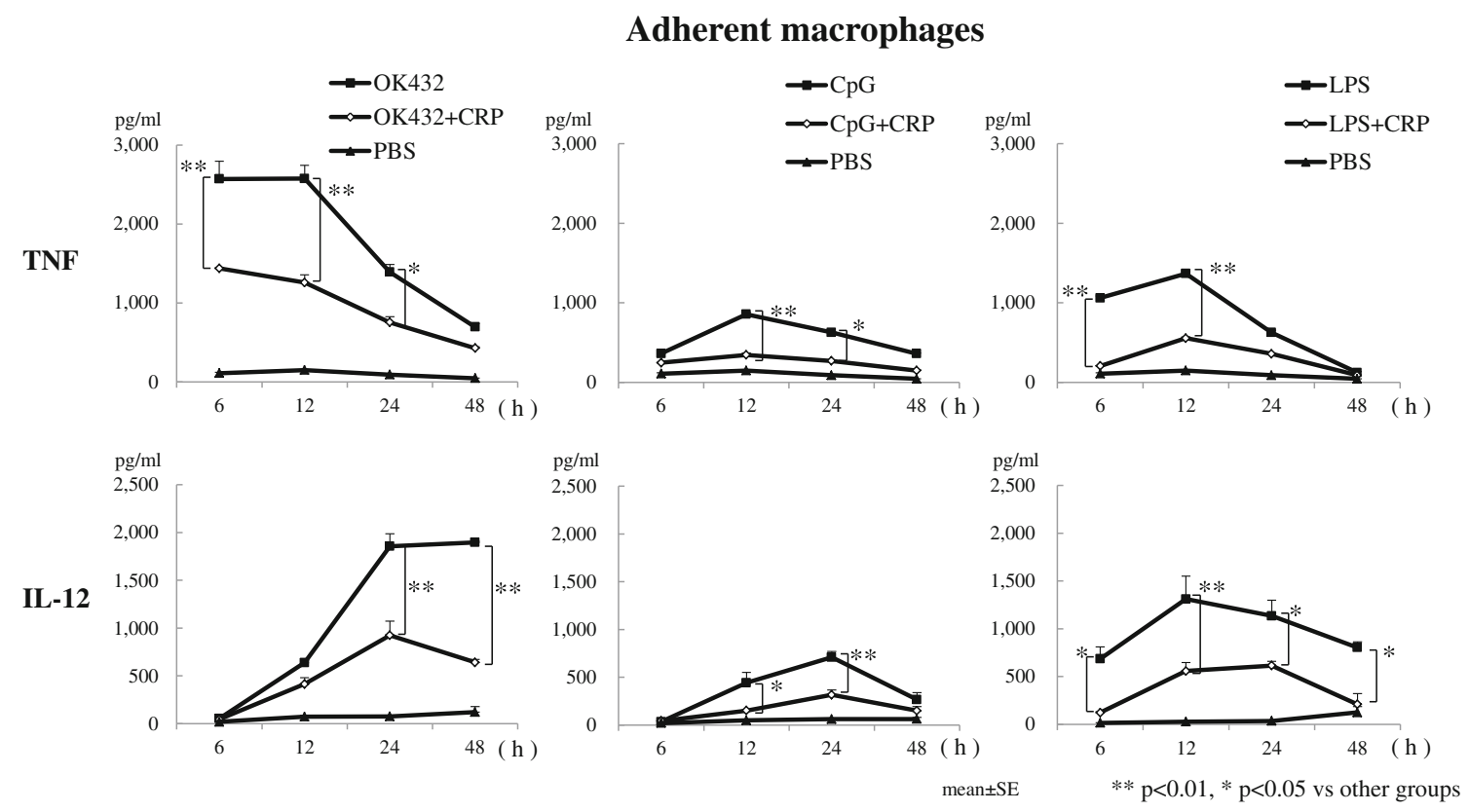

Fig. 2. Synthetic CRP modulates proinflammatory cytokine production from adherent macrophages stimulated with bacterial reagents. Adherent macrophages were cultured with bacterial reagents with or without CRP for $48 \mathrm{~h}$. The culture supernatants were collected at the indicated time points and were subjected to an ELISA for TNF and IL-12 (p40 and p70). The data are presented as the means \pm SE from six independent experiments. $*^{* *} p<0.01$ vs CRP (+) group by two-way ANOVA. 


\section{CRP Treatment Reduces HMGB1 Production by PBMCs or Adherent Macrophages}

HMGB1 was recently shown to be secreted by macrophages, and is a late mediator of septic shock and lethality induced by either LPS or CpG-ODN [17]. Therefore, we next examined whether CRP affects HMGB1 secretion. We observed that the HMGB1 levels stimulated by the three reagents or the in vitro Shwartzman reaction were substantially inhibited by CRP treatment in both PBMCs (Fig. 6a) and macrophages (Fig. 6b).

\section{DISCUSSION}

TLR family is a phylogenetically conserved family of proteins that mediate innate immune reactions and are essential for microbial recognition [19]. LPS (a gramnegative bacterial component) and CpG-ODN (unmethylated common bacterial DNA of a specific sequence) engage TLR4 and TLR9, respectively. In addition, TLR2 can recognize lipoproteins/lipopeptides of gram-positive bacteria such as $S$. pyogenes. Macrophages recognize these bacterial components through TLRs and produce proinflammatory cytokines, including TNF and IL-12, to

\section{a PBMCs}

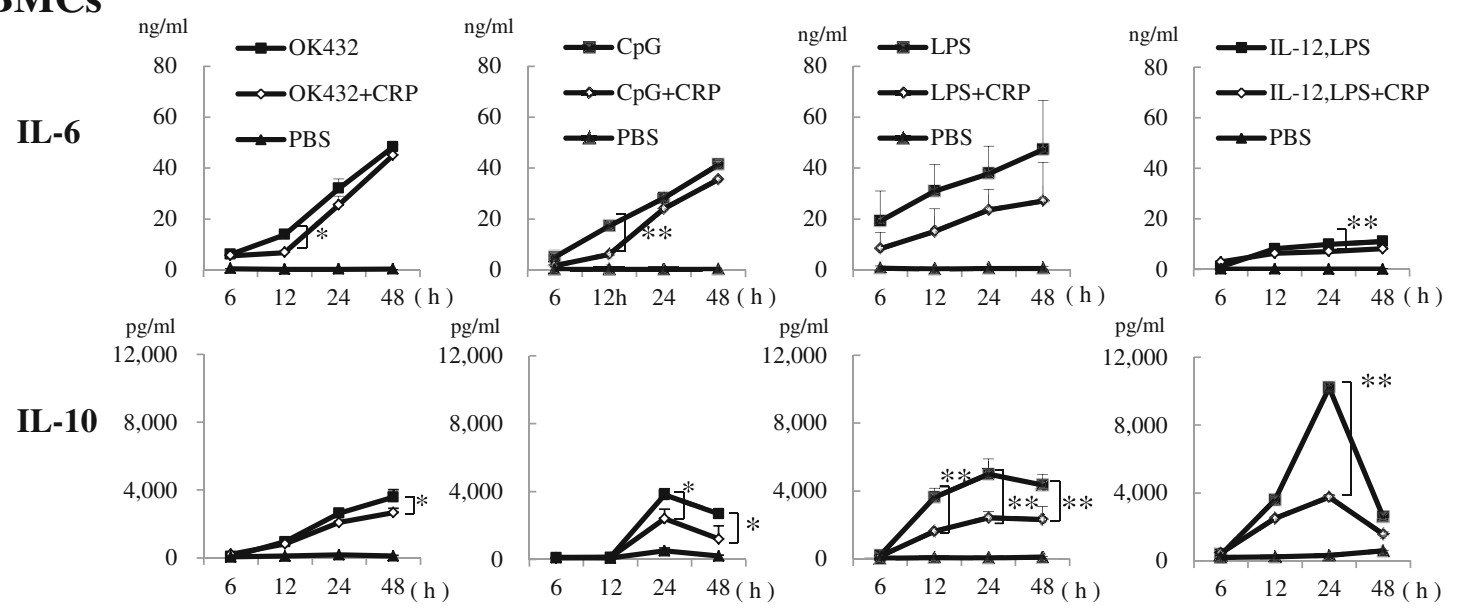

\section{b Adherent macrophages}

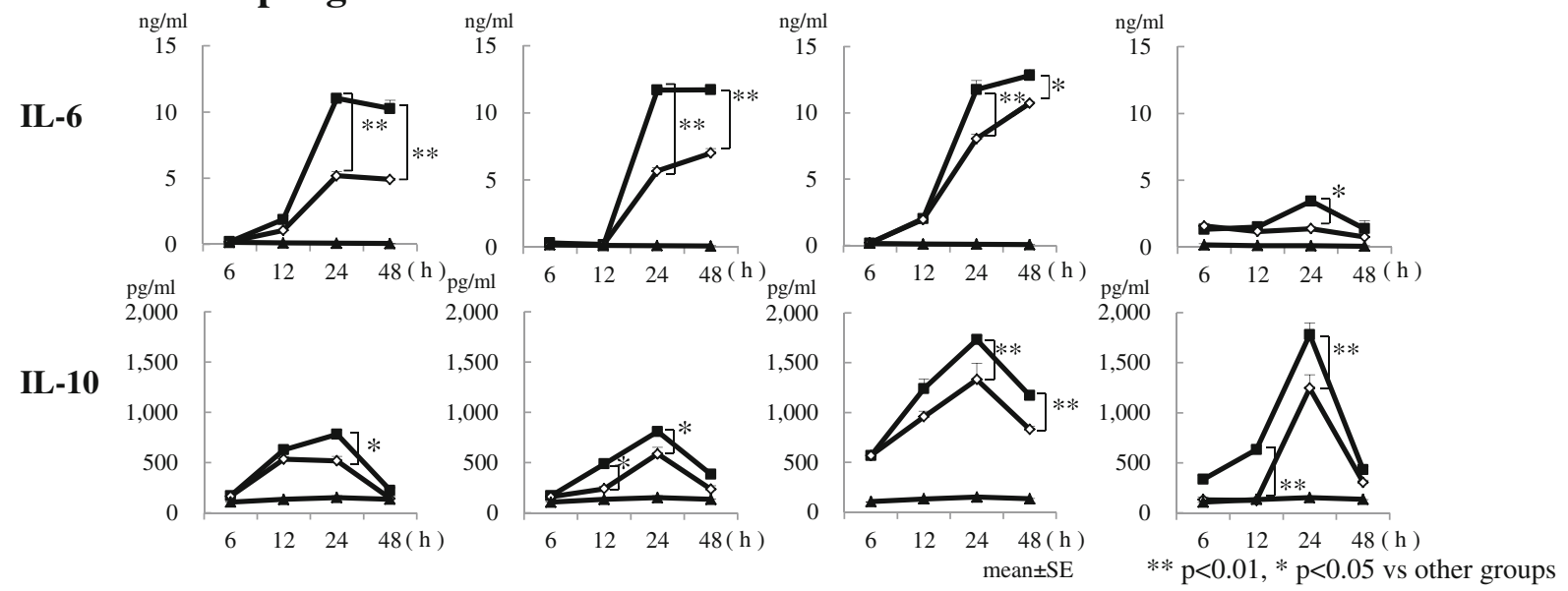

Fig. 3. Synthetic CRP modulates cytokine productions from bacterial reagent-stimulated PBMCs (a) and adherent macrophages (b). PBMCs or adherent macrophages were cultured with bacterial reagents with or without CRP for $48 \mathrm{~h}$. The culture supernatants were collected at the indicated time points and were subjected to an ELISA for IL-6 and IL-10. The data are presented as the means \pm SE from six independent experiments. $* * p<0.01, * p<0.05$ vs CRP $(+)$ group by two-way ANOVA. 
Table 1. The Effects of Synthetic CRP on the Cytotoxic Activities of PBMCs Stimulated with Bacterial Reagents

\begin{tabular}{|c|c|c|c|c|}
\hline \multirow[b]{2}{*}{ Target } & \multirow[b]{2}{*}{ Treatment of PBMCs } & \multicolumn{3}{|c|}{$\%$ Cytotoxicity at different $\mathrm{E} / \mathrm{T}$ ratios } \\
\hline & & $40: 1$ & $20: 1$ & \\
\hline \multirow[t]{4}{*}{ Raji } & Control (PBS) & $30.7 \pm 4.2$ & $21.4 \pm 1.3$ & \\
\hline & $\begin{array}{l}\text { OK432 } \\
\text { OK432 + CRP }\end{array}$ & $\left.\begin{array}{l}61.5 \pm 1.7 \\
76.3 \pm 3.6\end{array}\right] *$ & $\begin{array}{l}41.0 \pm 0.8 \\
64.3 \pm 4.0\end{array}$ & $*$ \\
\hline & $\begin{array}{l}\mathrm{CpG} \\
\mathrm{CpG}+\mathrm{CRP}\end{array}$ & $\left.\begin{array}{l}39.1 \pm 0.7 \\
44.0 \pm 1.4\end{array}\right] *$ & $\begin{array}{l}32.4 \pm 1.3 \\
39.5 \pm 1.3\end{array}$ & $* *$ \\
\hline & $\begin{array}{l}\text { LPS } \\
\text { LPS + CRP }\end{array}$ & $\left.\begin{array}{l}55.5 \pm 0.9 \\
58.3 \pm 0.8\end{array}\right] *$ & $\begin{array}{l}42.1 \pm 1.2 \\
50.8 \pm 1.8\end{array}$ & $* *$ \\
\hline \multirow[t]{4}{*}{ K562 } & Control (PBS) & $24.6 \pm 3.8$ & $17.3 \pm 1.5$ & \\
\hline & $\begin{array}{l}\text { OK432 } \\
\text { OK432 + CRP }\end{array}$ & $\left.\begin{array}{l}40.5 \pm 1.4 \\
53.0 \pm 2.7\end{array}\right] * *$ & $\left.\begin{array}{l}31.7 \pm 0.8 \\
36.5 \pm 1.0\end{array}\right]$ & ** \\
\hline & $\begin{array}{l}\mathrm{CpG} \\
\mathrm{CpG}+\mathrm{CRP}\end{array}$ & $\left.\begin{array}{l}32.1 \pm 0.6 \\
40.0 \pm 2.3\end{array}\right] *$ & $\begin{array}{l}27.7 \pm 0.9 \\
29.3 \pm 2.5\end{array}$ & \\
\hline & $\begin{array}{l}\text { LPS } \\
\text { LPS + CRP }\end{array}$ & $\left.\begin{array}{l}33.9 \pm 1.0 \\
39.5 \pm 1.7\end{array}\right] *$ & $\begin{array}{l}27.6 \pm 0.9 \\
29.8 \pm 2.6\end{array}$ & \\
\hline
\end{tabular}

Mean \pm SE vs other groups

${ }^{* *} p<0.01 ; * p<0.05$

Table 2. The Cytotoxic Activities of NK Cells or T Cell-depleted PBMCs

\begin{tabular}{|c|c|c|c|c|c|c|}
\hline \multirow[b]{2}{*}{ Target } & & & \multicolumn{4}{|c|}{$\%$ Cytotoxicity at different $\mathrm{E} / \mathrm{T}$ ratios } \\
\hline & & & \multicolumn{2}{|l|}{$40: 1$} & \multicolumn{2}{|l|}{$20: 1$} \\
\hline \multirow[t]{13}{*}{ Raji } & Control (PBS) & Total PBMCs & $30.7 \pm 4.2$ & & $21.4 \pm 1.3$ & \\
\hline & OK432 & Total PBMCs & $58.6 \pm 1.9$ & & $24.5 \pm 0.4$ & \\
\hline & & CD56 (-) PBMCs & $22.8 \pm 0.6$ & $* *$ & $17.6 \pm 0.9$ & ** \\
\hline & & CD57 (-) PBMCs & $59.8 \pm 1.3$ & & $38.3 \pm 1.1$ & \\
\hline & & T cell $(-)$ PBMCs & $56.1 \pm 1.6$ & & $26.5 \pm 0.6$ & \\
\hline & $\mathrm{CpG}$ & Total PBMCs & $44.4 \pm 2.0$ & $* *$ & $23.1 \pm 1.7$ & \\
\hline & & CD56 (-) PBMCs & $23.4 \pm 0.2$ & $* *$ & $17.4 \pm 1.7$ & \\
\hline & & CD57 (-) PBMCs & $39.4 \pm 0.9$ & & $31.8 \pm 0.6$ & \\
\hline & & T cell $(-)$ PBMCs & $44.1 \pm 2.5$ & & $23.1 \pm 0.1$ & \\
\hline & LPS & Total PBMCs & $62.0 \pm 1.3$ & & $41.0 \pm 0.5$ & $* *$ \\
\hline & & CD56 (-) PBMCs & $30.9 \pm 0.8$ & $* *$ & $28.8 \pm 0.5$ & $* *$ \\
\hline & & CD57 (-) PBMCs & $49.2 \pm 1.3$ & & $39.2 \pm 1.2$ & \\
\hline & & T cell (-) PBMCs & $56.2 \pm 0.4$ & & $37.4 \pm 1.9$ & \\
\hline \multirow[t]{13}{*}{ K562 } & Control (PBS) & Total PBMCs & $24.6 \pm 3.8$ & & $17.3 \pm 1.5$ & \\
\hline & OK432 & Total PBMCs & $41.9 \pm 1.5$ & & $24.5 \pm 0.4$ & $* *$ \\
\hline & & CD56 (-) PBMCs & $18.8 \pm 0.6$ & $* *$ & $17.6 \pm 0.7$ & $* *$ \\
\hline & & CD57 (-) PBMCs & $37.7 \pm 1.1$ & & $31.3 \pm 0.6$ & \\
\hline & & T cell (-) PBMCs & $37.7 \pm 1.0$ & & $26.5 \pm 0.6$ & \\
\hline & $\mathrm{CpG}$ & Total PBMCs & $30.8 \pm 2.4$ & & $18.0 \pm 1.2$ & \\
\hline & & CD56 (-) PBMCs & $20.9 \pm 1.4$ & $*$ & $16.4 \pm 0.8$ & \\
\hline & & CD57 (-) PBMCs & $29.8 \pm 1.2$ & & $26.9 \pm 0.7$ & \\
\hline & & T cell (-) PBMCs & $28.4 \pm 1.2$ & & $17.1 \pm 0.9$ & \\
\hline & LPS & Total PBMCs & $32.4 \pm 0.9$ & $*$ & $19.0 \pm 1.5$ & \\
\hline & & CD56 (-) PBMCs & $18.7 \pm 0.9$ & * & $18.3 \pm 0.6$ & \\
\hline & & CD57 (-) PBMCs & $30.5 \pm 1.1$ & & $28.0 \pm 1.1$ & \\
\hline & & T cell (-) PBMCs & $31.1 \pm 0.6$ & & $19.6 \pm 0.1$ & \\
\hline
\end{tabular}

Mean \pm SE vs other groups

$*^{*} p<0.01 ; * p<0.05$ 
activate NK cells and NKT cells to produce IFN- $\gamma$ and acquire antitumor activity [7]. Of particular interest, although synthetic CRP reduced IL-12 and TNF production from activated monocytes/macrophages which is a potent IFN- $\gamma$ inducer from NK/NKT cells, it did not inhibit IFN- $\gamma$ production from NK cells and T cells and augment antitumor cytotoxicity of NK cells.

CRP is elevated in septic patients in response to bacterial invasion, and peaks at $100 \sim 200 \mathrm{mg} / \mathrm{L}$ approximately $48 \mathrm{~h}$ after the onset of sepsis or exposure of bacterial toxins $[20,21]$. Native CRP is a pentraxin with a molecular weight of $115 \mathrm{kDa}[1,2]$. The synthetic CRP peptide used in the current study is a fragment of native CRP and homologous to amino acid residues
174-185 (Ile-Tyr-Leu-Gly-Gly-Pro-Phe-Ser-ProAsn-Val-Leu). The molecular weight is $1.3 \mathrm{kDa}$, which is about 100th of that of native CRP. The synthetic CRP has been reported to have a biological activity which is similar to that of native CRP $[3,4]$. We demonstrated that synthetic CRP generally suppressed the production of the proinflammatory cytokines, TNF, and IL-12, from human macrophages, whereas it did not affect the IFN- $\gamma$ production from NK cells and T cells. These results are consistent with our recent report in which synthetic CRP was found to decrease the serum TNF and IL-12 levels, but not IFN- $\gamma$ levels, after $E$. coli infection or endotoxin shock in mice [5]. CRP may exert its effect via binding to the Fc $\gamma$ RII $(\mathrm{CD} 32)$ of macrophages $[22,23]$ because
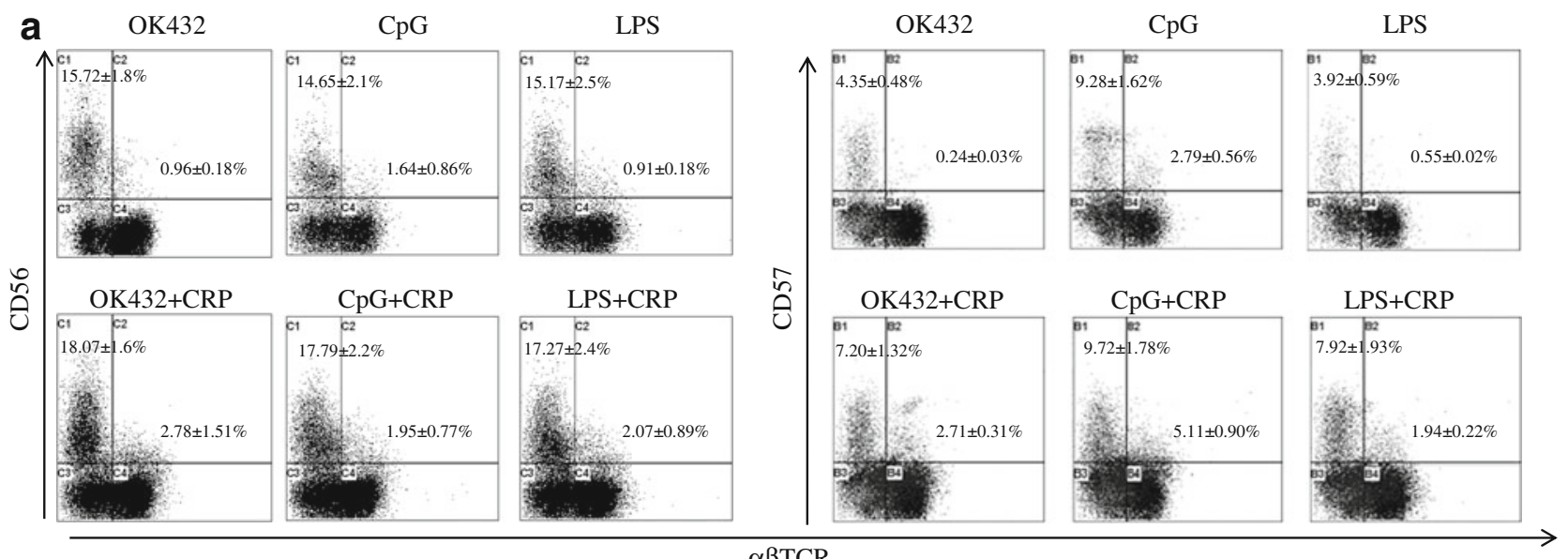

b

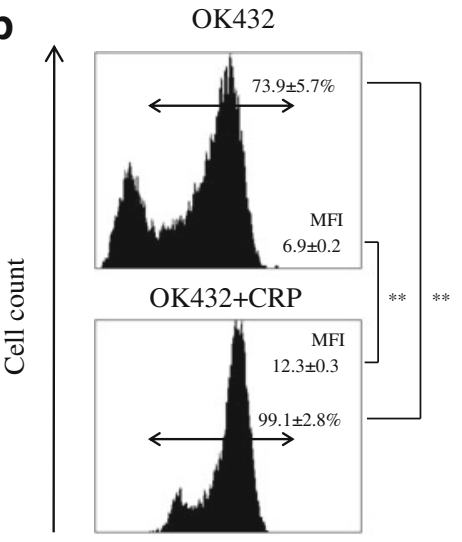

$\mathrm{CpG}$

LPS

Control(PBS)
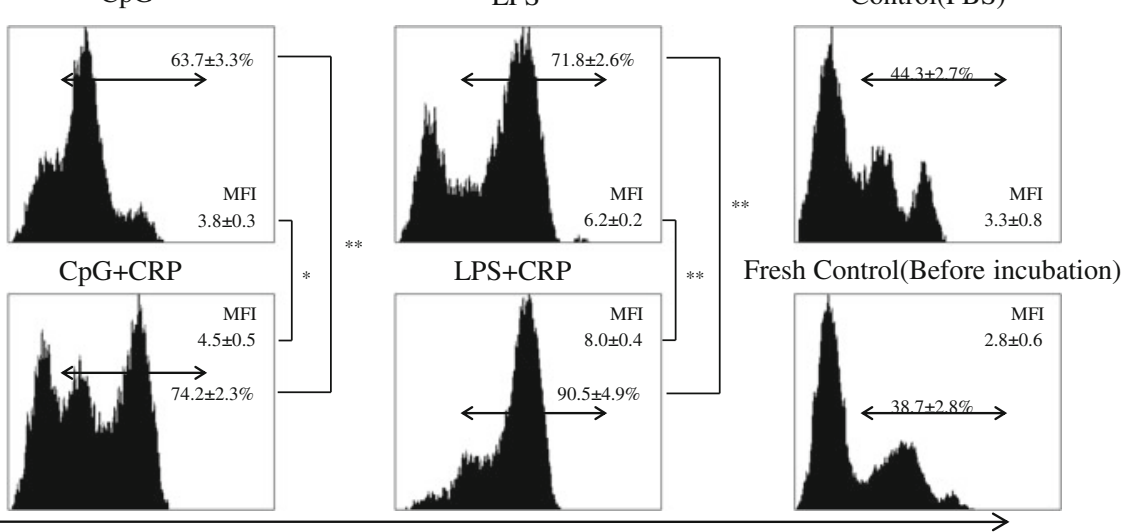

Perforin expression of CD56 $6^{+} \mathrm{NK}$ cells

mean $\pm \mathrm{SE} * * \mathrm{p}<0.01, * \mathrm{p}<0.05$ vs other groups

Fig. 4. Synthetic CRP increased the intracellular perforin in NK cells after bacterial stimulation. a The flow cytometric profile of CD56 ${ }^{+}$and $\mathrm{CD} 57^{+}$ NK cells after stimulation of PBMCs with bacterial reagents with or without synthetic CRP. b Perforin expression by the bacterial componentstimulated $\mathrm{CD}_{5} 6^{+} \mathrm{NK}$ cells. The intracellular perforin staining of CD56 ${ }^{+} \mathrm{NK}$ cells after OK432, CpG-ODN, or LPS stimulated PBMCs were cultured with or without CRP for $24 \mathrm{~h}$. PBMCs were obtained from healthy adult volunteers. MFI: mean fluorescence intensity. The data are presented are the means \pm SE from six independent experiments. 
CRP protected normal mice but not Fc $\gamma$ RII-deficient mice from LPS-induced mortality [22]. Although most NK cells express CD16 (Fc $\gamma$ RIII) but not CD32, CRP reportedly binds to NK cells and is involved in NK cell activity [24], suggesting that there is a still unknown receptor for CRP that may be present on NK cells. In addition, NK cells have both inhibitory (NKG2A) and stimulatory receptors (NKG2D, NKp30, p44, p46, etc.), and it is possible that CRP may activate NK cells by changing the balance of these receptors. Regardless of the mechanism, since CRP increases NK cell function despite the decreased IL-12 production from macrophages stimulated with bacterial reagents, it appears that CRP may bind to NK cells and directly affect their function under inflammatory conditions. These findings imply that the CRP co-administration with biological response modifiers (such as Streptococcus and CpGODN) to human cancers, may improve the antitumor effect of these reagents with reducing side effect induced by TNF.

Synthetic CRP modestly suppressed the production of IL-6 and IL-10 from PBMCs or adherent macrophages stimulated with bacterial reagents in vitro. IL-6 and IL-10 were mainly released from macrophages in response to tissue injury or inflammation [25], and IL-6 is the chief stimulator of the production of acute phase proteins including CRP [26]. IL-10 is a representative anti-proinflammatory cytokine and is important for the resolution of inflammation, although it sometimes aggravates bacterial infection [27]. Therefore, IL-6 and IL-10 may be important cytokines for maintaining the immune balance of hosts during infections. These results suggest that CRP modulates the cytokine milieu in order to not strongly suppress these cytokines.

CRP also greatly inhibited HMGB1 secretion from macrophages, which is now known to be a late mediator

\section{a PBMCs}
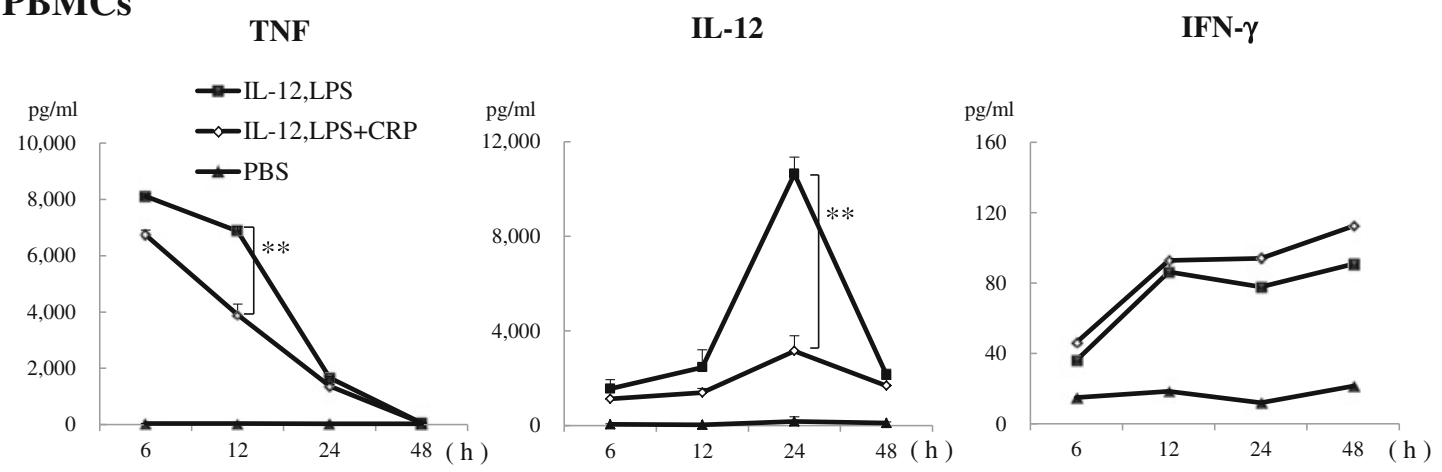

\section{b Adherent macrophages}

TNF

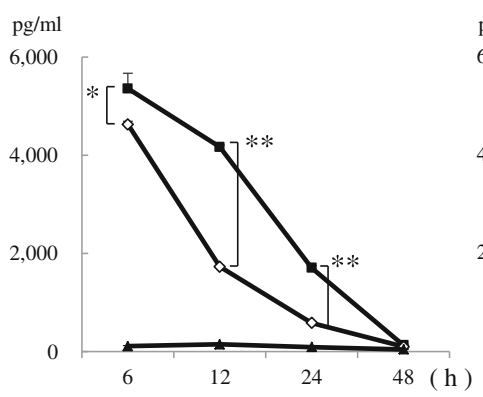

IL-12

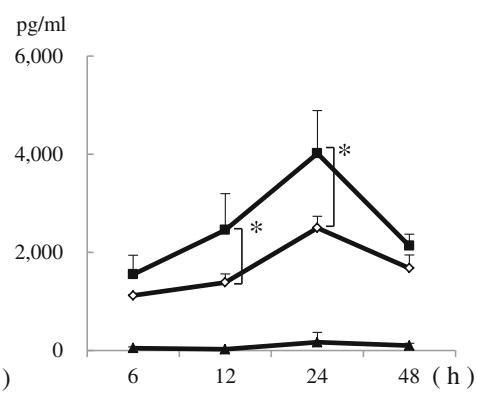

mean $\pm \mathrm{SE} \quad * * \mathrm{p}<0.01, * \mathrm{p}<0.05$ vs other groups

Fig. 5. The effect of synthetic CRP on cytokine production from PBMCs (a) and adherent macrophages (b) in the in vitro Shwartzman reaction. PBMCs or adherent monocytes/macrophages were cultured with IL-12 (p40 and p70) with or without CRP for 24 h. Subsequently, cells were further cultured with LPS for additional $24 \mathrm{~h}$. The culture supernatants were collected at the indicated time points and were subjected to an ELISA for TNF, IL-12 (p40\&p70) and IFN- $\gamma$. The data are presented as the means \pm SE from six independent experiments. ${ }^{* *} p<0.01,{ }^{*} p<0.05$ vs CRP $(+)$ group by two-way ANOVA. 
of septic shock and lethality induced by either LPS or CpG-DNA [17, 18]. Inside the cells, HMGB1 is present in the nucleus as well as the cytosol and binds to CpGODN provided by TLR9 [18]. When present outside of cells, HMGB1 acts as a strong inflammatory cytokinelike molecule [16]. Although TNF and IL-1 were considered to be the main effectors in septic shock [13], it is now clear that HMGB1 is an important late mediator of septic shock and the resultant MODS, and proinflammatory cytokines may be upstream regulators of HMGB1.

The Shwartzman reaction is an exaggerated form of endotoxin shock, in which lethal shock and MODS are steadily evoked in mice when they are injected with IL12 and a sublethal dose of LPS $16 \mathrm{~h}$ apart [13]. IFN- $\gamma$ production from NK/NKT cells during the IL-12 priming phase, and TNF production from macrophages/Kupffer cells after LPS stimulation are crucial for this phenomenon [14]. Shwartzman reaction-like phenomenon can be reproduced in human PBMCs in vitro when they are cultured with IL-12 for $24 \mathrm{~h}$ and subsequently cultured with LPS for additional $24 \mathrm{~h}$, in which a much larger amount of TNF is produced from macrophages than that produced from macrophages stimulated with LPS alone (in vitro Shwartzman reaction) [6], which is confirmed in this study and synthetic CRP decreased this phenomenon.

We have recently demonstrated in mice that the Kupffer cells in the liver are subdivided into two subsets, one is cytokine (IL-12 and TNF)-producing CD11b ${ }^{+}$ Kupffer cells and the other is CD68 ${ }^{+}$phagocytic Kupffer cells [28]. The $\mathrm{CD}^{+} 8^{+}$Kupffer cells with phagocytic activity predominate in the liver, but most of the macrophages in the spleen and blood are weakly phagocytic CD11b ${ }^{+}$cells [28]. Consistently, CRP did not significantly increase the phagocytic activity of human blood monocytes stimulated with LPS in vitro (less than $10 \%$ of monocytes phagocytose microbeads, unpublished observation). We speculated that, in contrast to Kupffer cells, blood monocytes essentially have weak phagocytic activity after LPS stimulation and the effect of CRP may therefore not be obvious.

\section{a HMGB1(PBMCs)}
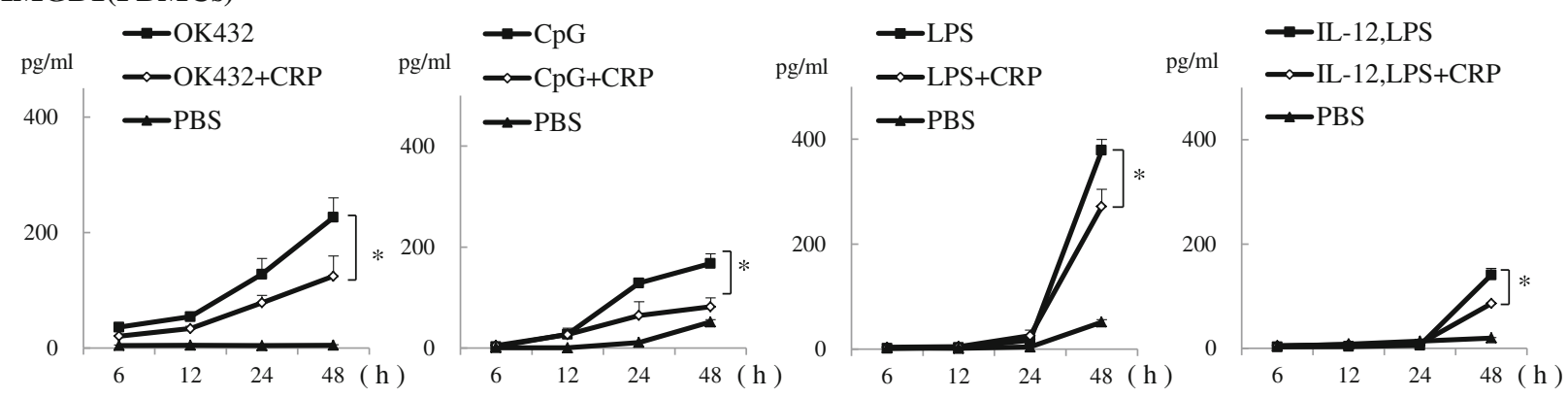

\section{b HMGB1(Adherent macrophages)}
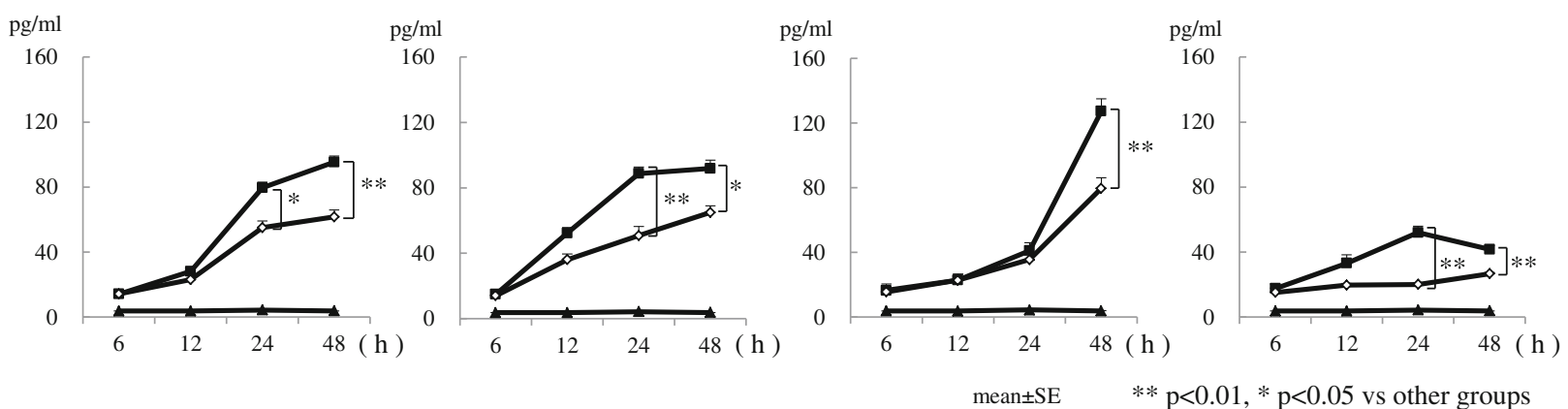

Fig. 6. HMGB1 production from PBMCs (a) and adherent macrophages (b) after bacterial stimulation and the in vitro Shwartzman reaction. PBMCs or adherent macrophages were cultured with the indicated bacterial reagents with or without CRP for $48 \mathrm{~h}$. The culture supernatants were collected at the indicated time points and were subjected to an ELISA for HMGB1. PBMCs or adherent macrophages were also similarly induced in vitro Shwartzman-like response to that described in Fig. 5 to measure HMGB1 production. The data are presented are the means \pm SE from six independent experiments. $* * p<0.01, * p<0.05$ vs CRP $(+)$ group by two-way ANOVA. 
Notably, CRP augmented the cytotoxicity of NK cells against tumor cell lines, which may be explained by increased perforin expression of $\mathrm{CD} 56^{+} \mathrm{NK}$ cells after stimulation with bacterial components and CRP. CRP alone did not induce cytokine production, increase the cytotoxicity of NK cells, nor increase the number of NK cells in PBMCs (our unpublished observations), suggesting that CRP may exert its effects only in the presence of a bacterial infection or inflammation.

Our present in vitro results using human PBMCs also showed that CRP overall inhibits the excessive inflammatory immune response without reducing cellular immunity or the $\mathrm{T}$ helper 1 immune response (IFN- $\gamma$ ). CRP also activates complement system and binds to $\mathrm{Fc}$ receptor of phagocytes, thereby increasing the opsonization of microbes [23]. In addition, synthetic CRP treatment increased endogenous CRP production in mice with bacterial infection [5]. Furthermore, CRP (human or rabbit)-transgenic mice are resistant to LPS challenge, and not only to $S$. pneumoniae infection but also to gram negative bacterial infection (Salmonella enterica serovar Typhimurium) [29-31]. Since severe bacterial infections or septic shock in humans are usually induce high serum CRP levels but often accompanied by the hepatocyte injury (which produce CRP), synthetic CRP treatment may additionally cover the effect of endogenous CRP.

It is noteworthy that synthetic CRP peptide decreased the TNF production in mice with lethal endotoxin shock or the Shwartzman reaction, but did not reduce the TNF production in mice with lethal $E$. coli infection, although CRP treatment improved the mortality in all of these mice [5]. These findings suggest that CRP did not decrease TNF production from macrophages when it was required for mice to survive a severe bacterial infection, suggesting that CRP specifically, delicately and appropriately regulates the innate immunity depending on the circumstances.

Many cancers arise from the sites of infection, chronic irritation and inflammation [32]. In addition, several investigators have suggested that elevation of circulating CRP levels may be related to the cancer risk and/or prognoses [33, 34]. This may also be the case for ischemic heart disease and ischemic cerebrovascular disease. Nevertheless, a recent study demonstrated that high levels of CRP may not be directly involved in the induction of ischemic heart and cerebrovascular diseases [35]. These and current findings suggest that CRP may reflect the inflammatory condition of the patients and CRP itself may not be involved in the induction of cancers and ischemic vascular diseases.
Taken together, the present findings indicate that CRP is a strong and sophisticated modulator of innate immune leukocytes, implying its therapeutic potential in human septic shock.

\section{REFERENCES}

1. Volanakis, J.E. 2001. Human C-reactive protein: expression, structure, and function. Molecular Immunology 38: 189-197.

2. Du Clos, T.W. 2000. Function of C-reactive protein. Annals of Medicine 32: 274-278.

3. Barna, B.P., M.J. Thomassen, M. Maier, S.V. Medendorp, R.R. Tubbs, T. Chiang, P. Zhou, B. Yen-Lieberman, S. Singh-Burgess, and S.D. Deodhar. 1994. Combination therapy with a synthetic peptide of C-reactive protein and interleukin 2: augmented survival and eradication of pulmonary metastases. Cancer Immunology, Immunotherapy 38: 38-42.

4. Zhong, W., Q. Zen, J. Tebo, K. Schlottmann, M. Coggeshall, and R.F. Mortensen. 1998. Effect of human C-reactive protein on chemokine and chemotactic factor-induced neutrophil chemotaxis and signaling. Journal of Immunology 161: 2533-2540.

5. Inatsu, A., M. Kinoshita, H. Nakashima, J. Shimizu, D. Saitoh, S. Tamai, and S. Seki. 2009. Novel mechanism of C-reactive protein for enhancing mouse liver innate immunity. Hepatology 49: 2044 2054.

6. Motegi, A., M. Kinoshita, K. Sato, N. Shinomiya, S. Ono, S. Nonoyama, H. Hiraide, and S. Seki. 2006. An in vitro Shwartzman reaction-like response is augmented age-dependently in human peripheral blood mononuclear cells. Journal of Leukocyte Biology 79: 463-472.

7. Kawabata, T., M. Kinoshita, A. Inatsu, Y. Habu, H. Nakashima, N. Shinomiya, and S. Seki. 2008. Functional alterations of liver innate immunity of mice with aging in response to CpG-oligodeoxynucleotide. Hepatology 48: 1586-1597.

8. Seki, S., Y. Habu, T. Kawamura, K. Takeda, H. Dobashi, T. Ohkawa, and H. Hiraide. 2000. The liver as a crucial organ in the first line of host defense: the roles of Kupffer cells, natural killer (NK) cells and NK1.1 Ag+ $\mathrm{T}$ cells in $\mathrm{T}$ helper 1 immune responses. Immunology Reviews 174: 35-46.

9. Seki, S., H. Nakashima, and M. Kinoshita. 2012. The liver as a pivotal innate immune organ. Immuno-Gastroenterology 1: 76-89.

10. Lopez-Verges, S., J.M. Milush, S. Pandey, V.A. York, J. ArakawaHoyt, H. Pircher, P.J. Norris, D.F. Nixon, and L.L. Lanier. 2010. CD57 defines a functionally distinct population of mature NK cells in the human CD56dimCD16+ NK-cell subset. Blood 116: $3865-$ 3874.

11. Kawarabayashi, N., S. Seki, K. Hatsuse, T. Ohkawa, Y. Koike, T. Aihara, Y. Habu, R. Nakagawa, K. Ami, H. Hiraide, and H. Mochizuki. 2000. Decrease of CD56(+)T cells and natural killer cells in cirrhotic livers with hepatitis $\mathrm{C}$ may be involved in their susceptibility to hepatocellular carcinoma. Hepatology 32: 962 969.

12. Seki, S., H. Nakashima, M. Nakashima, and M. Kinoshita. 2011. Antitumor immunity produced by the liver Kupffer cells, NK cells, NKT cells, and CD8 CD122 T cells. Clinical \& Developmental Immunology: 868345.

13. Ozmen, L., M. Pericin, J. Hakimi, R.A. Chizzonite, M. Wysocka, G. Trinchieri, M. Gately, and G. Garotta. 1994. Interleukin 12, interferon gamma, and tumor necrosis factor alpha are the key cytokines of the generalized Shwartzman reaction. The Journal of Experimental Medicine 180: 907-915. 
14. Sato, K., M. Kinoshita, A. Motegi, Y. Habu, E. Takayama, S. Nonoyama, H. Hiraide, and S. Seki. 2005. Critical role of the liver $\mathrm{CD} 8+\mathrm{CD} 122+\mathrm{T}$ cells in the generalized Shwartzman reaction of mice. European Journal of Immunology 35: 593-602.

15. Shono, S., Y. Habu, M. Nakashima, A. Sato, H. Nakashima, H. Miyazaki, M. Kinoshita, G. Tsumatori, N. Shinomiya, and S. Seki. 2011. The immunologic outcome of enhanced function of mouse liver lymphocytes and kupffer cells by high-fat and highcholesterol diet. Shock 36: 484-493.

16. Kokkola, R., A. Andersson, G. Mullins, T. Ostberg, C.J. Treutiger, B. Arnold, P. Nawroth, U. Andersson, R.A. Harris, and H.E. Harris. 2005. RAGE is the major receptor for the proinflammatory activity of HMGB1 in rodent macrophages. Scandinavian Journal of Immunology 61: 1-9.

17. Wang, H., O. Bloom, M. Zhang, J.M. Vishnubhakat, M. Ombrellino, J. Che, A. Frazier, H. Yang, S. Ivanova, L. Borovikova, K.R. Manogue, E. Faist, E. Abraham, J. Andersson, U. Andersson, P.E. Molina, N.N. Abumrad, A. Sama, and K.J. Tracey. 1999. HMG-1 as a late mediator of endotoxin lethality in mice. Science 285: 248-251.

18. Yanai, H., T. Ban, Z. Wang, M.K. Choi, T. Kawamura, H. Negishi, M. Nakasato, Y. Lu, S. Hangai, R. Koshiba, D. Savitsky, L. Ronfani, S. Akira, M.E. Bianchi, K. Honda, T. Tamura, T. Kodama, and T. Taniguchi. 2009. HMGB proteins function as universal sentinels for nucleic-acid-mediated innate immune responses. Nature 462: 99-103.

19. Medzhitov, R., and C.A. Janeway Jr. 1997. Innate immunity: the virtues of a nonclonal system of recognition. Cell 91: 295-298.

20. Buttenschoen, K., D.C. Buttenschoen, D. Berger, C. Vasilescu, S. Schafheutle, B. Goeltenboth, M. Seidelmann, and H.G. Beger. 2001. Endotoxemia and acute-phase proteins in major abdominal surgery. American Journal of Surgery 181: 36-43.

21. Tschaikowsky, K., M. Hedwig-Geissing, J. Schmidt, and G.G. Braun. 2011. Lipopolysaccharide-binding protein for monitoring of postoperative sepsis: complemental to C-reactive protein or redundant? PLoS One 6: e23615.

22. Mold, C., W. Rodriguez, B. Rodic-Polic, and T.W. Du Clos. 2002. C-reactive protein mediates protection from lipopolysaccharide through interactions with Fc gamma R. Journal of Immunology 169: 7019-7025.

23. Bodman-Smith, K.B., R.E. Gregory, P.T. Harrison, and J.G. Raynes. 2004. FcgammaRIIa expression with FcgammaRI results in C-reactive protein- and IgG-mediated phagocytosis. Journal of Leukocyte Biology 75: 1029-1035.
24. Baum, L.L., K.K. James, R.R. Glaviano, and H. Gewurz. 1983 Possible role for C-reactive protein in the human natural killer cell response. The Journal of Experimental Medicine 157: 301-311.

25. Tateishi, Y., S. Oda, M. Nakamura, K. Watanabe, T. Kuwaki, T. Moriguchi, and H. Hirasawa. 2007. Depressed heart rate variability is associated with high IL-6 blood level and decline in the blood pressure in septic patients. Shock 28: 549-553.

26. Gabay, C., and I. Kushner. 1999. Acute-phase proteins and other systemic responses to inflammation. The New England Journal of Medicine 340: 448-454.

27. Hiraki, S., S. Ono, M. Kinoshita, H. Tsujimoto, S. Seki, and H. Mochizuki. 2007. Interleukin-18 restores immune suppression in patients with nonseptic surgery, but not with sepsis. American Journal of Surgery 193: 676-680.

28. Kinoshita, M., T. Uchida, A. Sato, M. Nakashima, H. Nakashima, S. Shono, Y. Habu, H. Miyazaki, S. Hiroi, and S. Seki. 2010 Characterization of two F4/80-positive Kupffer cell subsets by their function and phenotype in mice. Journal of Hepatology 53: 903910

29. Szalai, A.J., D.E. Briles, and J.E. Volanakis. 1995. Human Creactive protein is protective against fatal Streptococcus pneumoniae infection in transgenic mice. Journal of Immunology 155: $2557-2563$.

30. Xia, D., and D. Samols. 1997. Transgenic mice expressing rabbit C-reactive protein are resistant to endotoxemia. Proceedings of the National Academy of Sciences of the United States of America 94: 2575-2580.

31. Szalai, A.J., J.L. VanCott, J.R. McGhee, J.E. Volanakis, and W.H. Benjamin Jr. 2000. Human C-reactive protein is protective against fatal Salmonella enterica serovar typhimurium infection in transgenic mice. Infection and Immunity 68: 5652-5656.

32. Coussens, L.M., and Z. Werb. 2002. Inflammation and cancer. Nature 420: 860-867.

33. Allin, K.H., and B.G. Nordestgaard. 2011. Elevated C-reactive protein in the diagnosis, prognosis, and cause of cancer. Critical Reviews in Clinical Laboratory Sciences 48: 155-170.

34. Woo, Y., W.J. Hyung, K. Obama, H.I. Kim, K.H. Pak, T. Son, and S.H. Noh. 2012. Elevated high-sensitivity C-reactive protein, a marker of advanced stage gastric cancer and postgastrectomy disease recurrence. Journal of Surgical Oncology 105: 405-409.

35. Zacho, J., A. Tybjaerg-Hansen, J.S. Jensen, P. Grande, H. Sillesen, and B.G. Nordestgaard. 2008. Genetically elevated C-reactive protein and ischemic vascular disease. The New England Journal of Medicine 359: 1897-1908. 